\title{
DIFERENÇA NOS HÁBITOS ALIMENTARES ENTRE ALUNOS DO \\ ENSINO REGULAR E ENSINO INOVADOR DA ESCOLA DE ENSINO \\ MÉDIO IRMÃO LEO
}

Elis Regina MAZZURANA*

*Bióloga, M.Sc, Professora UNIARP. Email: elismazzurana@gmail.com

Recebido em: 08/12/2015 - Aprovado em: 13/07/2016 - Disponibilizado em: 18/12/2016

\begin{abstract}
RESUMO:
O presente trabalho teve como objetivo conhecer a diferença nos hábitos alimentares entre os alunos do Ensino Médio Regular e Ensino Médio Inovador da Escola de Ensino Médio Irmão Leo, bem como verificar a qualidade da alimentação destes alunos, baseando-se nos princípios da alimentação equilibrada. Esta pesquisa foi conduzida com os alunos do Ensino Médio diurno da Escola de Ensino Médio Irmão Leo, em Caçador/SC, durante o mês de julho de 2015, com 148 alunos do Ensino Regular e 69 alunos do Ensino Inovador, totalizando 217 alunos. A coleta de dados ocorreu por meio de questionário contendo 16 questões fechadas. Os dados foram compilados e transformados em gráficos, por meio da planilha eletrônica (Calc) do LibreOffice.Concluiu-se que os alunos, principalmente os do Ensino Inovador, consomem grande variedade de alimentos necessários para uma alimentação saudável e equilibrada, como legumes, verduras e frutas, o que provavelmente deve estar relacionado à alimentação fornecida pela escola, entretanto, ainda é necessário fazer um bom trabalho de reeducação alimentarpara que os alunos melhorem seus hábitos alimentares.
\end{abstract}

Palavras-chave: Alunos. Adolescentes. Alimentação. Escola.Ensinomédio.

\section{DIFFERENCE IN EATING HABITS AMONG REGULAR EDUCATION AND INNOVATIVE EDUCATION STUDENTS OF IRMÃO LEO HIGH SCHOOL}

\begin{abstract}
:
This study aimed to know the difference in eating habits between students from the Regular High School and Innovative High School at Irmão Leo High School, as well as checking the quality of feeding of students, based on the principles of balanced diet. This research was conducted with the students of the High School at Irmão Leo High School, in Caçador / SC, during the month of July 2015, with 148 students of regular education and 69 students of innovative education, totaling 217 students. The data were collected through a questionnaire containing 16 closed questions. Data were compiled and turned into graphics, through the spreadsheet (Calc) LibreOffice. It was concluded that students, especially those in the innovative education, consume a variety of foods needed for a healthy and balanced diet, such as vegetables and fruits, which should probably be related to food provided by the school, however, is still necessary do a good job of nutritional education for students to improve their eating habits.
\end{abstract}

Keywords: Students. Teens.Alimentation.School.High School.

\section{INTRODUÇÃO}

Desde os primeiros momentos da vida a alimentação está entrelaçada com emoções, simbolismos e influências socioeconômicas e culturais, sendo fator essencial para manutenção da saúde e da qualidade de vida
(EISENSTEIN et al., 2000). A alimentação escolar no Brasil é coordenada pelo Programa Nacional de Alimentação Escolar (Pnae), que tem a função de contribuir para o crescimento, o desenvolvimento, a aprendizagem, o rendimento escolar e principalmente a formação de hábitos alimentares saudáveis, 
por meio da oferta da alimentação escolar e de ações de educação alimentar e nutricional (FNDE, 2015).

O Pnae atende os alunos de toda a educação básica matriculados em escolas públicas, filantrópicas e em entidades comunitárias, por meio da transferência de recursos financeiros, incluindo as escolas estaduais de Santa Catarina, entre elas, a Escola de Ensino Médio Irmão Leo.

$\mathrm{Na}$ Escola de Ensino Médio Irmão Leo há duas modalidades de ensino: Ensino Médio Regular e Ensino Médio Inovador. Os alunos que estudam no sistema de Ensino Médio Regular, período Matutino ou Vespertino, fazem o lanche fornecido pela escola durante o período de estudo. Já os alunos do Ensino Médio Inovador permanecem na escola o dia todo, em três dias da semana (terça-feira, quarta-feira e quinta-feira), onde fazem o lanche da manhã, almoçam e fazem o lanche da tarde. A cardápio escolar é elaborado por nutricionista, sendo que os alimentos são preparados e fornecidos rigorosamente de acordo com o cardápio. É importante ressaltar que dois cardápios são fornecidos à escola, um cardápio para alimentação dos alunos do Ensino Médio Regular e outro para os alunos do Ensino Médio Inovador.

Neste cenário, acredita-se que os hábitos alimentares dos alunos podem variar de acordo com a disponibilidade de alimentos fornecidos, havendo diferença nos hábitos alimentares entre os alunos do Ensino Médio
Regular e Ensino Médio Inovador. Assim, surgiu a ideia de diagnosticar os hábitos alimentares dos alunos das duas modalidades de ensino, para que a partir dos resultados obtidos promovam-se ações no ambiente escolar no intuito de melhorar a qualidade da alimentação e também se realizematividades de reeducação alimentar, auxiliando no processo de construção de hábitos saudáveis.

Este trabalho teve por objetivo conhecer a diferença nos hábitos alimentares entre os alunos do Ensino Médio Regular e Ensino Médio Inovador da Escola de Ensino Médio Irmão Leo, bem como verificar a qualidade da alimentação destes alunos, baseando-se nos princípios da alimentação equilibrada.

\section{MATERIAL E MÉTODOS}

Esta pesquisa foi conduzida com os alunos do Ensino Médio da Escola de Ensino Médio Irmão Leo, localizada na Rua Conselheiro Mafra, 750 - Centro, na cidade de Caçador/SC. A pesquisa foi realizada com os alunos do período diurno, durante o mês de julho de 2015, sendo 148 alunos do Ensino Médio Regular e 69 alunos do Ensino Médio Inovador, totalizando 217 alunos.

A coleta de dados ocorreu por meio de um questionário baseado na obra de Souza; Silva (2010) e na pirâmide dos alimentos de Philippi (2008), contendo 16 questões fechadas que abordaram hábitos de vida e de 
alimentação dos alunos. Para conhecer os hábitos alimentares, as perguntas do questionário foram separas por grupo alimentar de acordo com a pirâmide dos alimentos, onde as opções de resposta eram: consome sempre (4 a 7 vezes por semana), consome às vezes (1 a 3 vezes por semana) ou nunca consome. Os questionários foram respondidos em sala de aula, onde cada aluno recebeu um questionário a ser preenchido e as devidas orientações para realização do procedimento.

Após aplicação dos questionários os dados foram compilados e posteriormente apresentados na forma de gráficos por meio da planilha eletrônica (Calc) do LibreOffice.

\section{APRESENTAÇÃO DOS} RESULTADOS

A pesquisa foi realizada com 148 alunos do Ensino Médio Regular e 69 alunos do Ensino Médio Inovador, que apresentaram idade entre 14 a 18 anos, sendo considerados adolescentes, pois de acordo com o Ministério da Saúde, em consonância com a OMS, a adolescência corresponde à segunda década da vida, compreendendo o período de 10 a 19 anos de idade (VASCONCELOS, 2012).

No Ensino Regularo número de estudantes do sexo masculino e feminino quase não diferiu, totalizando $51 \%$ do sexo masculino e $49 \%$ do sexo feminino (Figura 1). Entretanto, no Ensino Inovador há maior número de pessoas do sexo feminino, sendo $58 \%$ (Figura 1).

Os alunos do Ensino Regular não almoçam na escola, enquanto $88 \%$ dos alunos do Ensino Inovador almoçam na escola.Alguns alunos do Ensino Inovador (12\%)preferem almoçar fora da escola, assim, eles saem no horário de almoço e voltam no período vespertino para a continuidade das aulas, então esses alunos consomem apenas o lanche, no período matutino e vespertino.

Quanto ao número de refeições diárias, há maior porcentagem de alunos do Ensino Inovador que fazem de 5 a 6 refeições diariamente(Figura 2), isso provavelmente deve-se ao fato de que esses alunos se alimentam basicamente na escola, onde é servido lanche da manhã, almoço e lanche da tarde.

Numa observação geral, tanto os alunos do ensino regular quanto os alunos do ensino inovador, bebem em torno de $500 \mathrm{~mL}$ a 1L de água por dia (Figura 3). De acordo com Philippi (2008) a água é um nutriente fundamental à vida e desempenha diversas funções orgânicas, sendo sua ingestão diária essencial à saúde e a média diária de ingestão oral de água, pelo adulto, é de 1La 3L. Eisenstein et al. (2000) recomenda 4 a 6 copos de água por dia, ou seja, de $1 \mathrm{~L}$ a 1,5L, para adolescentes.

A grande maioria dos alunos, mais de 50\%, tanto do Ensino Regular quanto do Ensino Inovador, praticam atividades físicas 
de 2 a 3 vezes por semana (Figura 4). É importante salientar que nas duas modalidades de ensino, os alunos têm duas aulas de Educação Física por semana de 45 minutos cada, que também foram contabilizadas no momento de responder ao questionário. Os alunos do Ensino Inovador fazem outras atividades esportivas além das aulas de educação física, como vôlei, futsal, dança e judô.

Quanto aos hábitos alimentares, o consumo diário de carboidratos é realizado por mais de $70 \%$ dos alunos das duas modalidades de ensino (Figura 5).Eisenstein et al. (2000) e Giannini (2007) recomendam ingestão de carboidratos em torno de 55 a $60 \%$ da energia total da dieta, sendo que os carboidratos são as principais fontes de energia para os adolescentes.

Os carboidratos são alimentos que devem ser ingeridos em grande quantidade por atuarem principalmente no centro da saciedade hipotalâmica, afetando a ingestão subsequente dos demais alimentos, pela oxidação e transformação em calorias, no fígado (EISENSTEINet al., 2000).

Em torno de $50 \%$ dos alunos, das duas modalidades de ensino, fazem o consumo de leite, queijo e iogurte diariamente (Figura 6).Vasconcelos (2012) afirma que é comum os adolescentes trocarem a ingestão do leite por líquidos de alta densidade energética como refrigerantes e sucos artificiais, comprometendo a ingestão de cálcio, por isso, ressalta-se a importância de manter no cardápio alimentos lácteos.

A maioria dos alunos tem o hábito de consumir legumes, verduras e frutas semanalmente. Cerca de $50 \%$ dos alunos do Ensino Regular e quase $70 \%$ dos alunos do Ensino Inovador fazem o consumo de legumes e verduras de 1 a 3 vezes por semana (Figura 7).

O consumo de frutas ocorre diariamente em mais de $50 \%$ dos alunos do Ensino Inovador, enquanto nos alunos do Ensino Regular fica em torno de $40 \%$ (Figura 8). Mais de $40 \%$ dos alunos das duas modalidades de ensino consomem frutas de 1 a 3 vezes por semana (Figura 8).

Esses resultados podem estar relacionados com a alimentação fornecida pela escola, que apresenta no cardápio grande variedade de legumes, verduras e frutas. Como os alunos do Ensino Inovador almoçam na escola três dias por semana, fazem a maior parte de suas refeições no ambiente escolar, consumindo o que é oferecido no cardápio, o que pode interferir diretamente nos hábitos alimentares.

O consumo de feijão e oleaginosas teve resultados muito parecidos entre a frequência de consumo nas duas modalidades de ensino, sendo que em torno de $40 \%$ consomem diariamente, $30 \%$ consomem de 1 a 3 vezes por semana e $10 \%$ nunca o consomem (Figura 9). 
O consumo de vitaminas e sais minerais deve ser dobrado durante a adolescência, pois os adolescentes incorporam o dobro da quantidade de cálcio, ferro, zinco e magnésio em seus organismos durante o período de crescimento (GIANNINI, 2007).

A grande maioria dos alunos consome carnes e ovos diariamente, sendo pouco mais de $60 \%$ dos alunos do Ensino Regular e mais de $70 \%$ dos alunos do Ensino Inovador (Figura 10).

De acordo com Vasconcelos (2012) a ingestão insuficiente de proteína na adolescência é rara, entretanto devem ser oferecidos na alimentação escolar diversos tipos de carnes, além dos ovos, sendo estes alimentos ricos em proteínas de alto valor biológico e essenciais durante a adolescência, já que a utilização de proteínas está fortemente ligada ao padrão de crescimento e pode representar uma porção substancial da dieta. Eisenstein et al. (2000) e Giannini (2007) afirmam que durante a adolescência há necessidade de ingestão de proteínas de 12 a $15 \%$ do total calórico, devido à formação de novos tecidos que promovem o crescimento.

Quase $60 \%$ dos alunos das duas modalidades de ensino fazem consumo de doces diariamente (Figura 11), e em torno de $50 \%$ dos alunos fazem consumo de óleos e gorduras de 1 a 3 vezes por semana (Figura 12).
O consumo de guloseimas, como salgadinhos, refrigerantes, chocolates e doces, ocorre diariamente em mais de $50 \%$ dos alunos, tanto do Ensino Regular quanto do Ensino Inovador (Figura 13).Carmo et al. (2006) verificou que 78,2\% dos adolescentes da rede pública de ensino da cidade de Piracicaba-SP ultrapassam a recomendação de ingestão máxima de 2 porções/dia de doces; e consomem $230 \mathrm{~mL}$ e $550 \mathrm{~mL}$ de refrigerante e bebidas com adição de açúcar, respectivamente.

A frutose, monossacarídeo encontrado em refrigerantes, é metabolizada principalmente pelo fígado, tornando-se responsável pelo aumento de peso em muitos adolescentes (EISENSTEINetal., 2000). Portanto, a ingestão de alimentos doces deve ser controlada para que não ocasione distúrbios alimentares dos estudantes.

É importante ressaltar que o presente estudo deve ser analisado e utilizado com cautela, pois os dados se referem apenas a frequência de consumo por grupo alimentar, entretanto não se sabe o número de porções ingeridas diariamente pelos adolescentes, já que o estudo tinha por objetivo conhecer os hábitos alimentares e através dos resultados desenvolver projetos estimulando a alimentação saudável e de qualidade. 
FIGURA 1 - Sexo

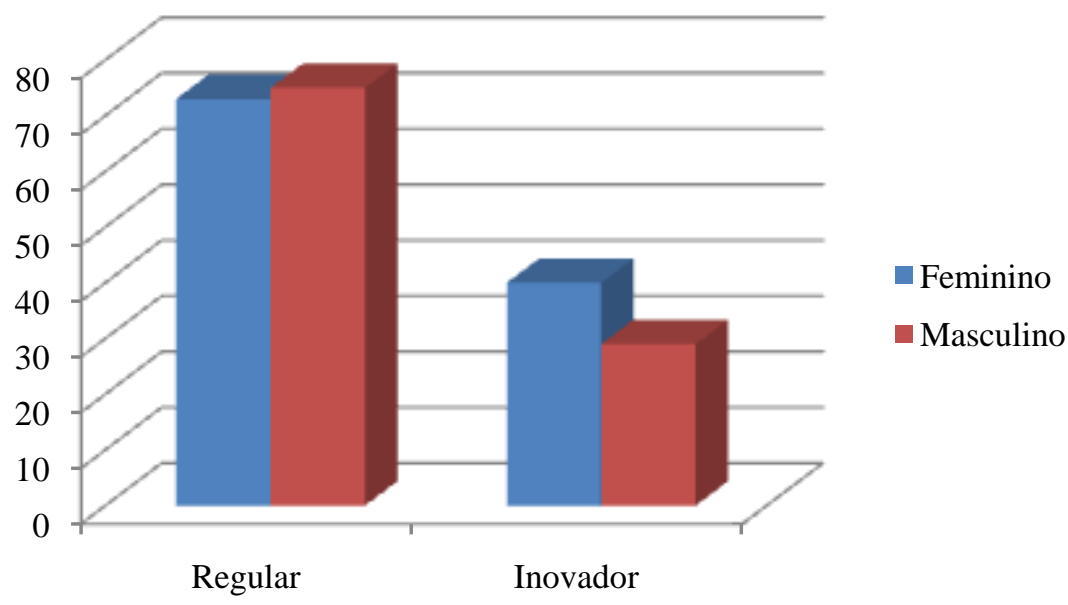

FIGURA 2 - Número de refeições diárias

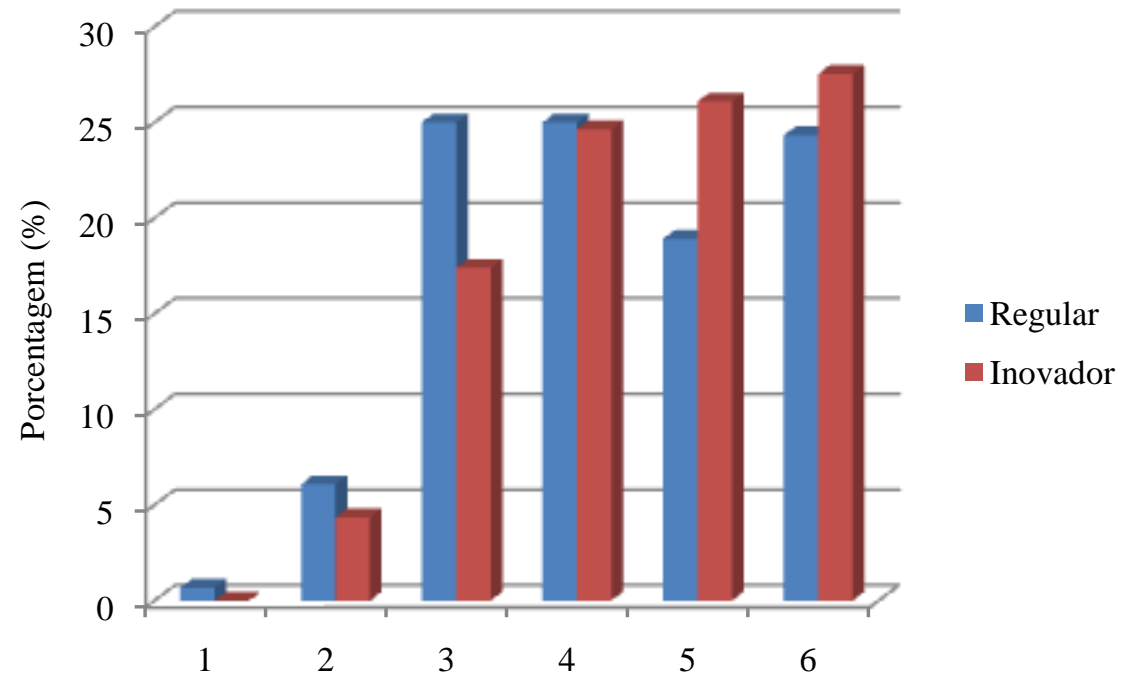

FIGURA 3 - Ingestão diária de água

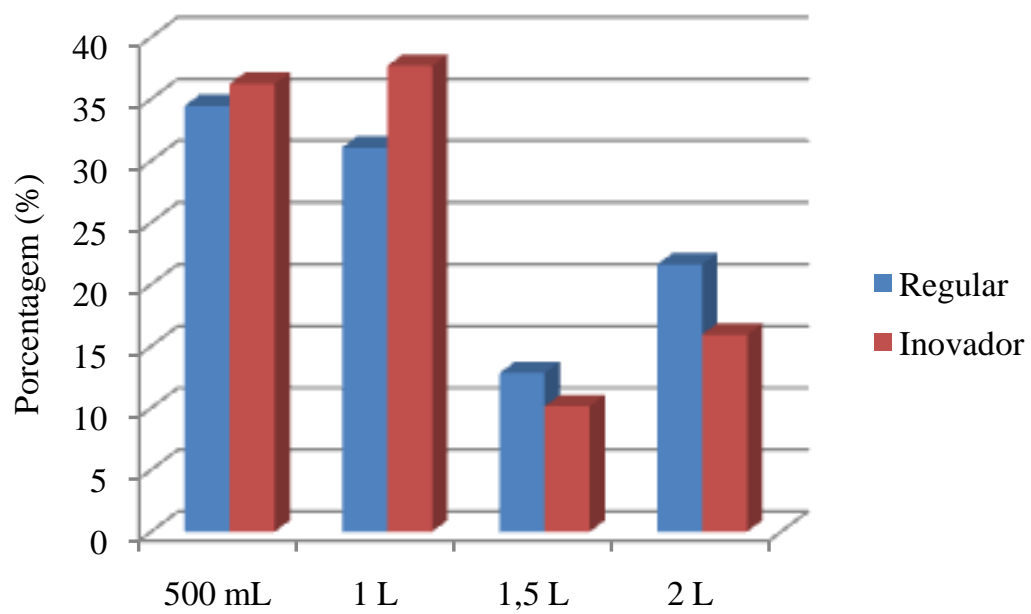


FIGURA 4 - Prática de atividade física

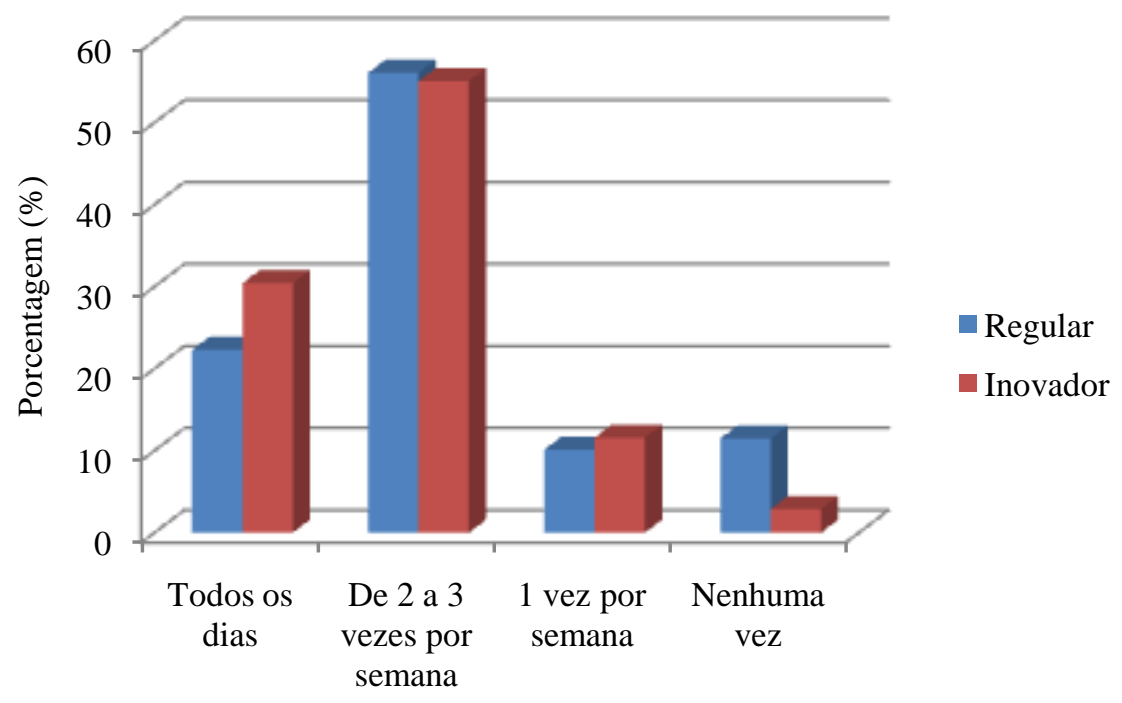

FIGURA 5 - Consumo semanal de carboidratos

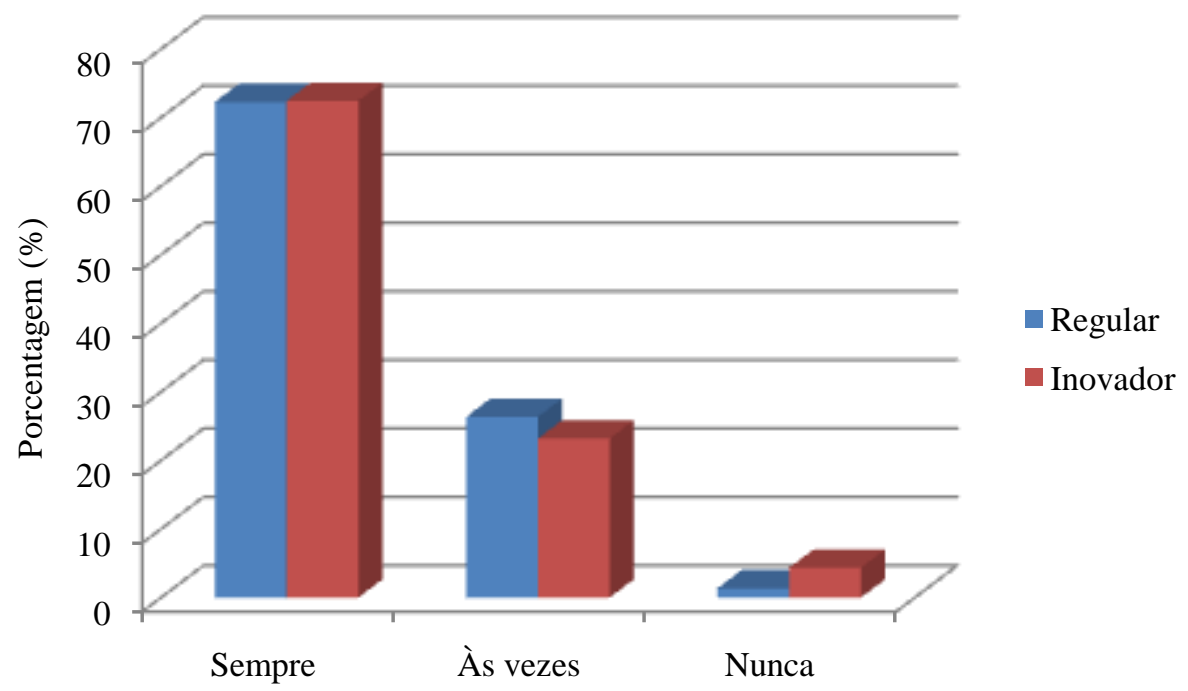

FIGURA 6 - Consumo semanal de leite, queijo e iogurte

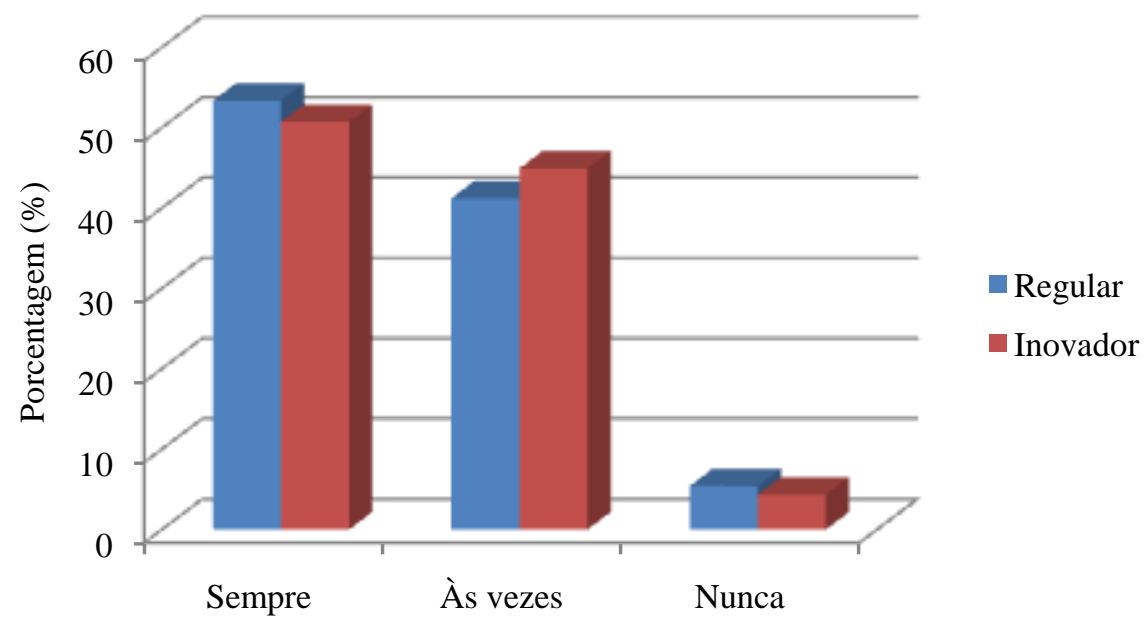


FIGURA 7 - Consumo semanal de legumes e verduras

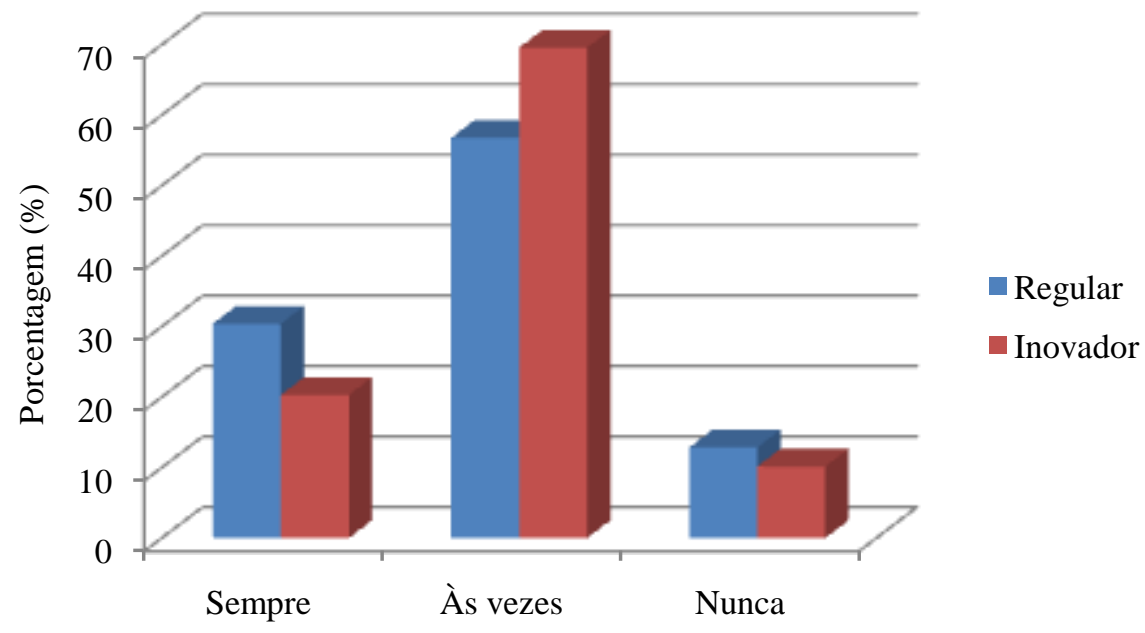

FIGURA 8 - Consumo semana de frutas

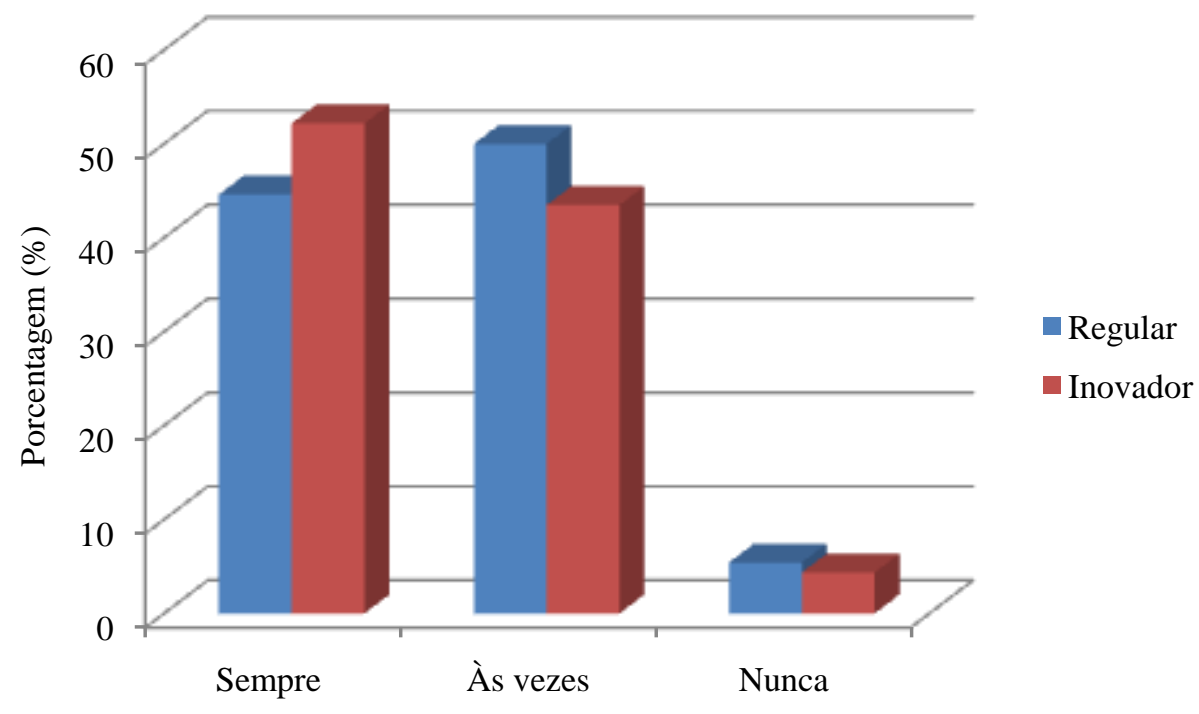

FIGURA 9 - Consumo semanal de feijões e oleaginosas

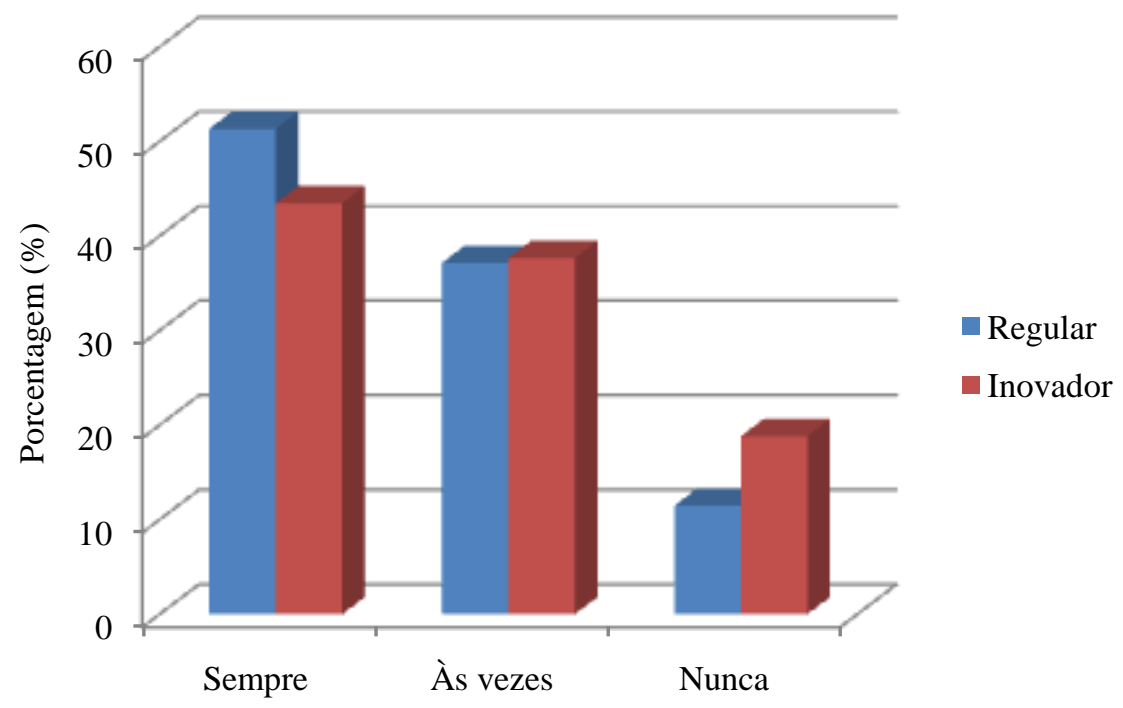


FIGURA 10 - Consumo semanal de carnes e ovos

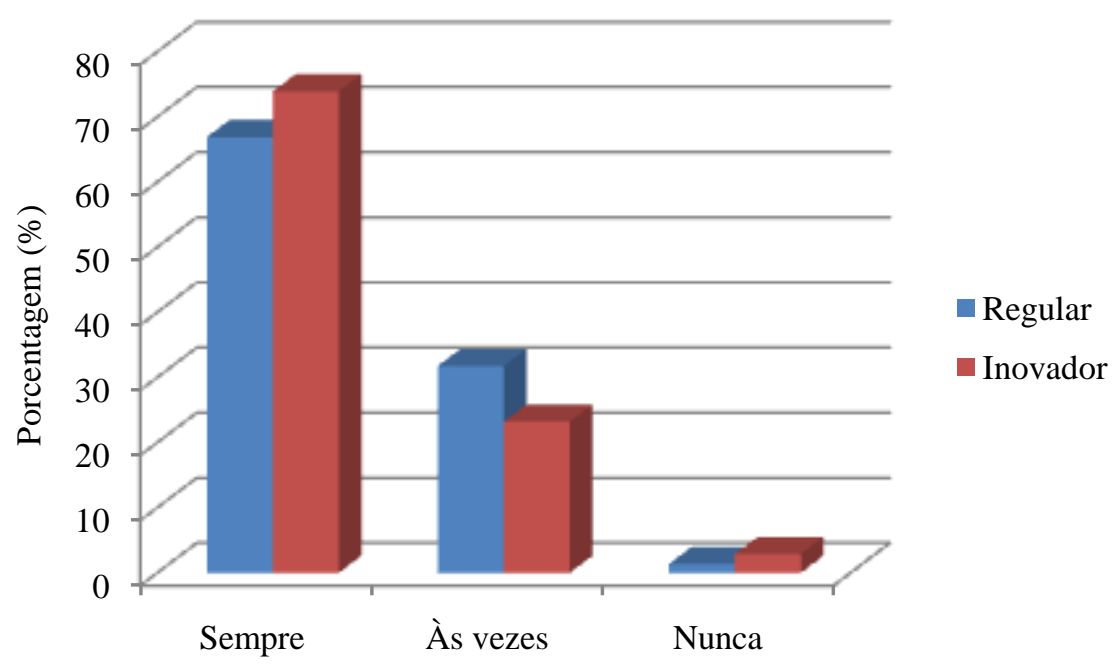

FIGURA 11 - Consumo semanal de açúcares e doces

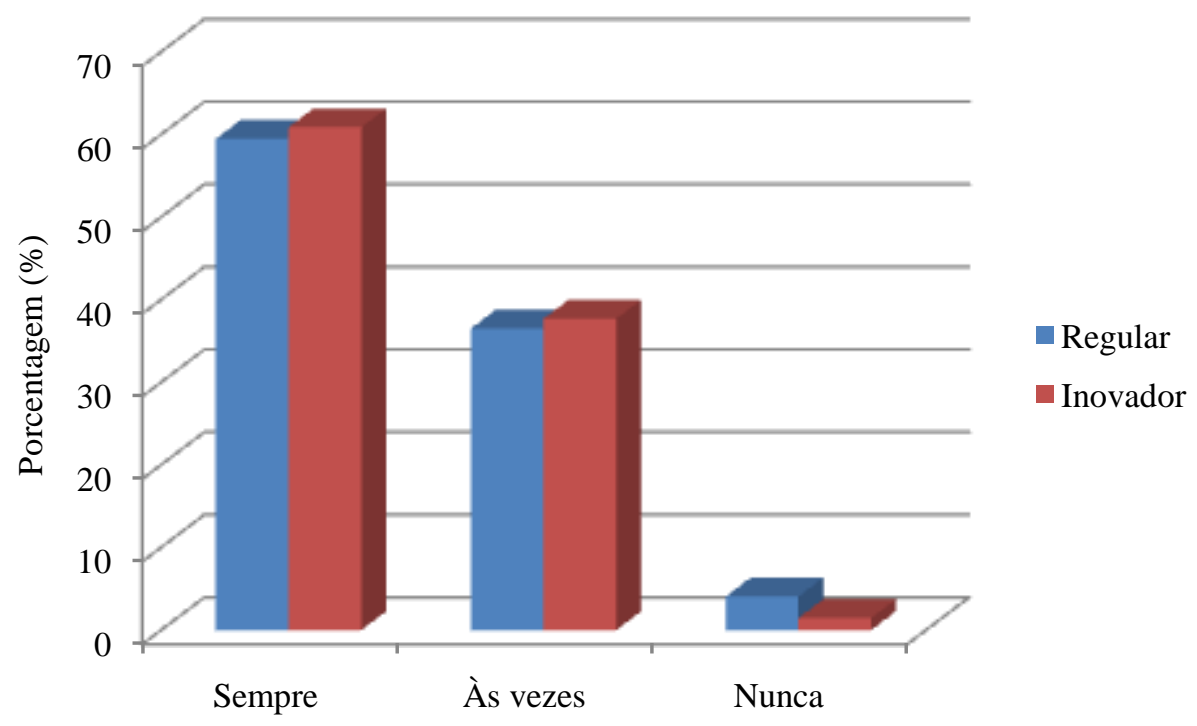

FIGURA 12 - Consumo semanal de óleos e gorduras

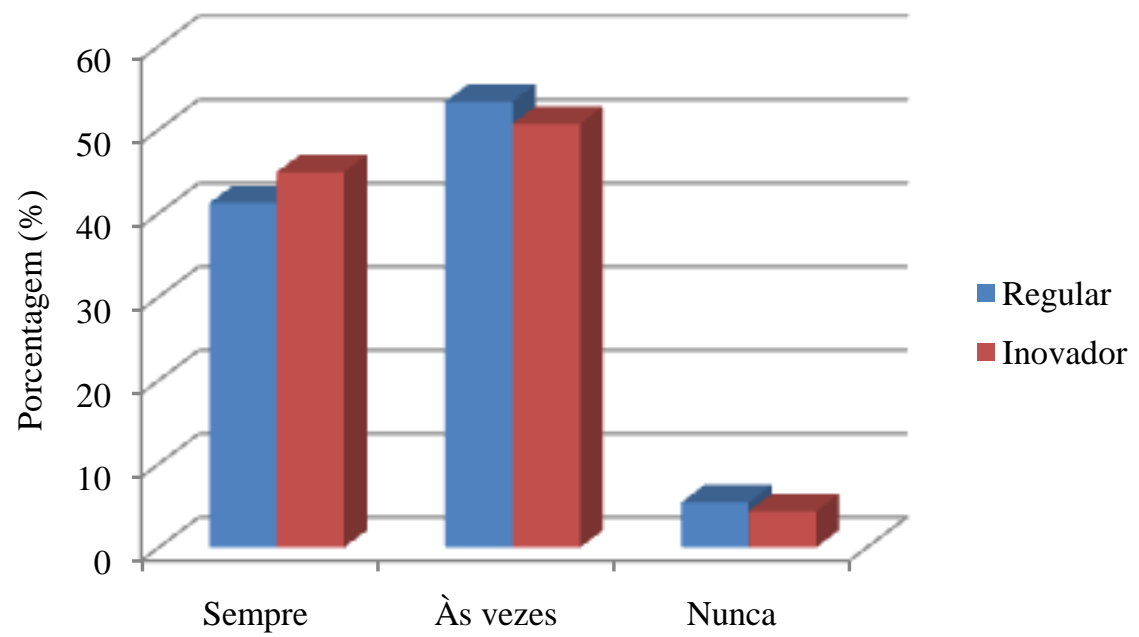


FIGURA 13 - Consumo semanal de guloseimas

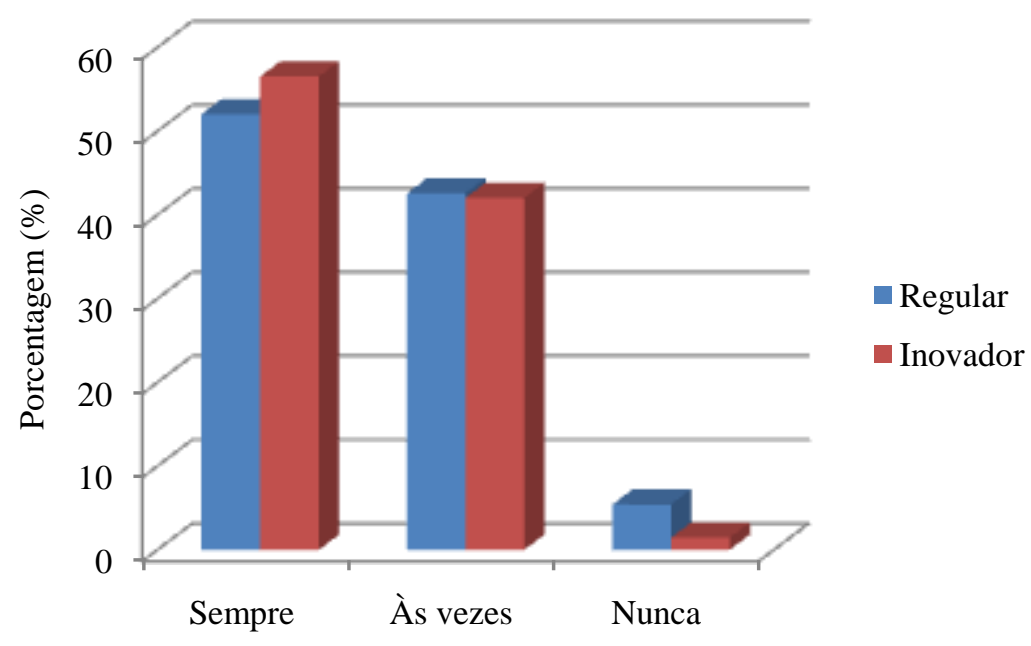

\section{CONCLUSÕES}

Por meio dos resultados, concluiu-se que os alunos do Ensino Inovador realizam maior número de refeições diárias e consomem com mais frequência legumes, verduras, frutas, carnes e ovos, em relação aos alunos do Ensino Regular. Esses resultados são importantes devido à necessidade dobrada da ingestão de vitaminas e sais minerais durante a adolescência, sendo que a maior ingestão desses alimentos pode estar relacionada com a alimentação fornecida pela escola, pois os alimentos necessários para uma alimentação equilibrada e saudável são fornecidos diariamente e de acordo com as porções adequadas nas refeições realizadas no ambiente escolar, salientando a importância da alimentação escolar na vida dos estudantes.

Entretanto, percebeu-se também a baixa ingestão de água e o alto consumo de guloseimas tanto no Ensino Regular quanto no Ensino Inovador, o que indica que são dois pontos fortes que deverão nortear as ações promovidas pela escola no sentido de orientar sobre alimentação e hábitos de vida saudáveis.

\section{REFERÊNCIAS}

CARMO, Marina Bueno doet al. Consumo de doces, refrigerantes e bebidas com adição de açúcar entre adolescentes da rede pública de ensino de Piracicaba, São Paulo. Revista

Brasileira de Epidemiologia, v.9, n.1, p. 121-130, 2006.

EISENSTEIN, Evelynet al. Nutrição na adolescência. Jornal de Pediatria, v.76, supl.3, p.262-274, 2000.

FNDE, Fundo Nacional de Desenvolvimento da Educação. Sobre o Pnae. Disponível em: <http://www.fnde.gov.br/programas/alimenta cao-escolar/alimentacao-escolarapresentacao>. Acesso em: 03 set. 2015.

GIANNINI, Denise Tavares. Recomendações nutricionais do adolescente. Adolescência \& Saúde, v.4, n.1, fev., p.12-18, 2007.

PHILIPPI, Sonia Tucunduva (Org.).

Pirâmide dos alimentos: fundamentos básicos da nutrição. Barueri: Manole, 2008. 
SOUZA,Cassiana Espíndola de; SILVA, Ana Beatriz Giovanonida. Consumo alimentar habitual dos trabalhadores de uma empresa do Vale do Taquari-RS. Revista Destaques

Acadêmicos, ano 2, n.3, p.19-25, 2010.

VASCONCELOS, Francisco de Assis Guedes de (Org.). Manual de orientação para a alimentação escolar na educação infantil, ensino fundamental, ensino médio e na educação de jovens e adultos. 2. ed. Brasília: PNAE: CECANE-SC, 2012. 